\title{
Winds and rain: the role of the biotic pump
}

\author{
Keywords: biotic pump theory, cloud-forming, \\ evapotranspiration, rainforests, condensation, airflow
}

\section{Introduction}

Climatologists view forests as important sinks of carbon dioxide in the form of biomass and their destruction as contributing as much as one third to global warming, but could forests, and in particular rainforests, be playing an unaccounted role in the hydrological cycle and the flow of humid surface air? In 2007, Anastassia Makarieva ${ }^{1}$ and Victor Gorshkov mathematician/physicists at the Nuclear Physics Institute, St Petersburg, Russia, came up with a startling new theory which maintained that the rainforest, by means of its high rate of transpiration, not only generated the mass of rain-bearing clouds which are a predominant feature of such continental regions, like the Amazon and Congo Basins, but was responsible for the winds bearing water vapour generated over the ocean by means of solar evaporation. In forming clouds, the transpired water-vapour, undergoes condensation and when the droplets of liquid water coalesce to form drops which then precipitate, the atmosphere loses molecular mass. According to the theory, the Biotic Pump theory (BPT), the subsequent drop in pressure causes the air above the rainforest to ascend to cloud-forming altitude. The mass of air replacing the rising air is the stream of humid air passing over the ocean.

The biotic pump theory therefore implies that the rainforest is responsible in the main for the flow of the Trade Winds, for instance, from Africa to Brazil. That being the case, the flow of air from the tropical ocean to the same latitude land mass will bring rain and enable the rainforest to flourish and grow deep into the hinterland. In effect, as one progresses deeper and deeper into the continent, the supply of rain will be maintained by the twin processes of rainforest evapotranspiration and the drawing in of humid air from the ocean by means of the pressure changes resulting from cloud-forming. As the Brazilian physicist, Eneas Salati, showed in the 1980s, the water vapour from evapotranspiration, accounting for more than 50 per cent

\author{
Volume 6 Issue 5 - 2020
}

\author{
Peter Bunyard \\ Independent researcher, UK \\ Correspondence: Peter Bunyard, Independent researcher, \\ Cornwall, UK, Tel +44 7740404819, \\ Email pbecologist@gn.apc.org \\ Received: December 07, 2020 | Published: December 18, \\ 2020
}

of rainfall, gets recycled at least five times over the Brazilian Amazon and another once or twice before the airstream reaches the Andes.

The knee-jerk reaction of most climatologists has been to reject the biotic pump theory. They explain the mass circulation of the tropical air masses as being the result of latitudinal temperature differences which cause hot air to rise and cold air to sink. Nevertheless, that widely accepted explanation is problematic. It fails, for example, to explain how the Chocó rainforest, a few degrees north of the equator, along Colombia's Pacific coast, receives up to 12 metres of rain each year, when the general flow of the winds from Central and South America is in the contrary direction, across the Pacific Ocean away from Colombia and towards Indonesia and Australia. However, observations from satellites show that a proportion of the Trade winds, crossing the Pacific from Central and South America, abruptly switches direction and then doubles back to hit the coast at $4^{\circ}$ North of the Equator. Could the forests of the Choco be the cause of that contraflow of air and therefore evidence for the biotic pump? And how come that the equatorial Colombian Amazon, some $2,500 \mathrm{~km}$ to the West of the Atlantic Ocean, receives as high a rainfall, some $2,400 \mathrm{~mm}$ of rain, as does the Eastern seaboard of the Brazilian Amazon? (Figure 1- Figure 5).

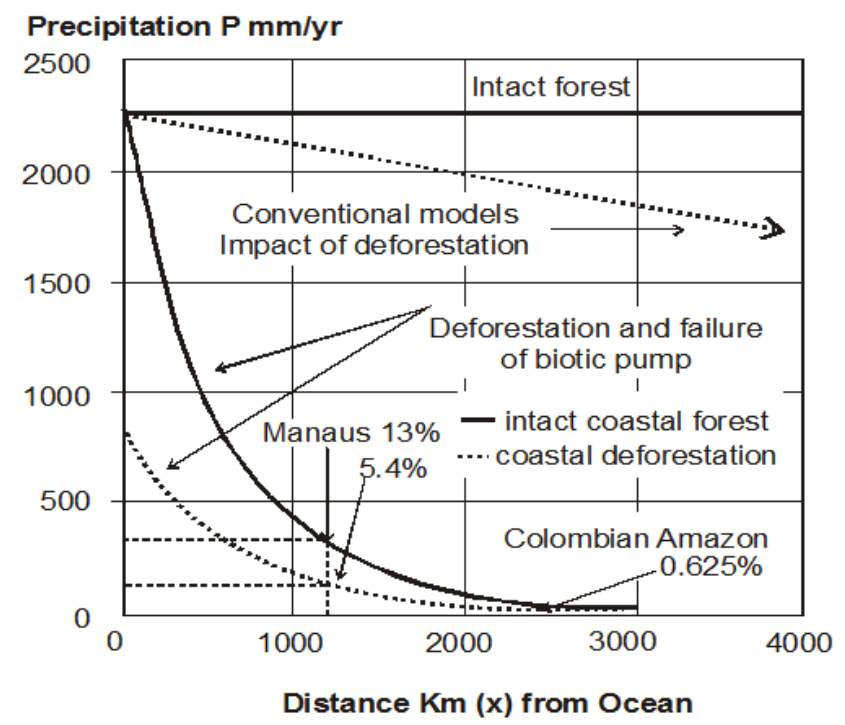

Figure I Deforestation impact according to the biotic pump theory. Makarieva \& Gorshkov (Makarieva A. M., 2007) use a length, l, of 600 km, as the distance over which a molecule of water will evaporate and fall-out through precipitation. The formula, $P_{X}=P_{0} \exp [-x / l] \quad$ describes the reduction in precipitation as the distance increases between the coast and inland. 

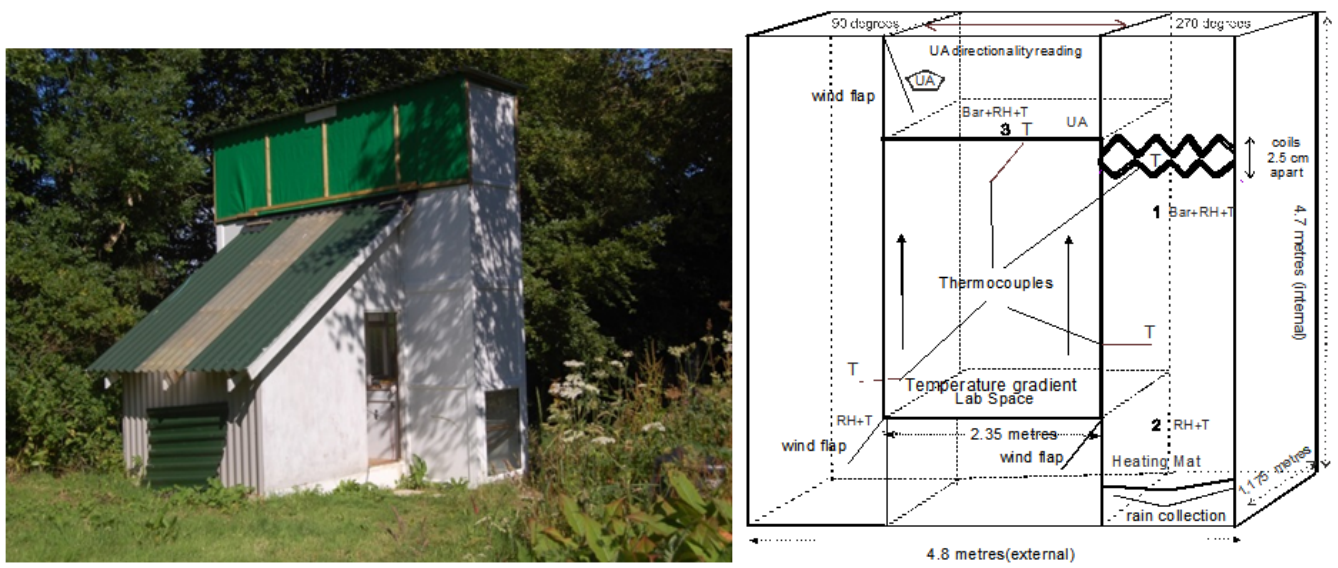

Figure 2 The experimental chamber for measuring absolute humidity changes and airflow. The lean-to is the laboratory.

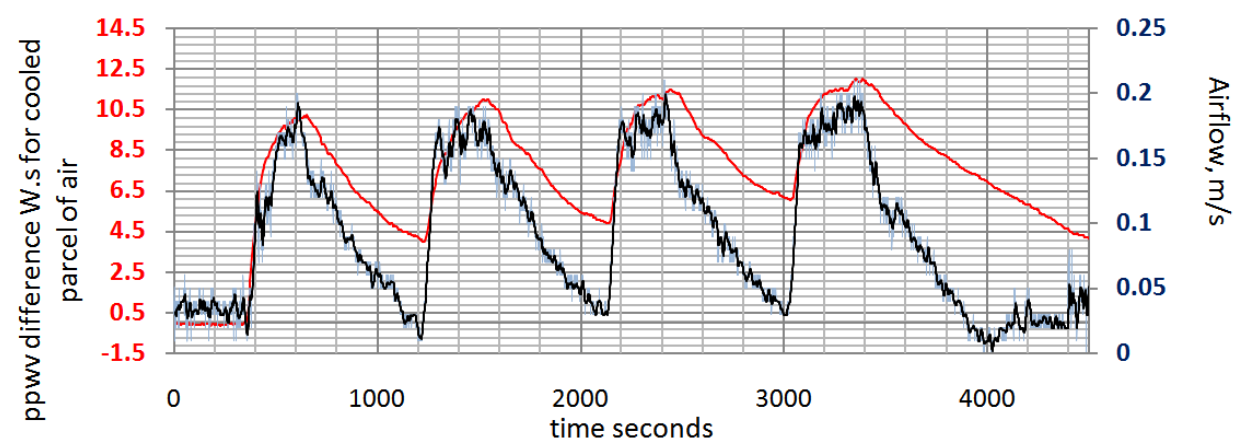

Figure 3 Experiment June 27th, 2016. The graph shows 4 refrigeration cycles. The left-hand axis shows the partial pressure change in water vapour in Watt. Seconds during the refrigeration cycle and the right-hand axis shows the anemometer readings. The directionality is clockwise and therefore down from the cooling coils.

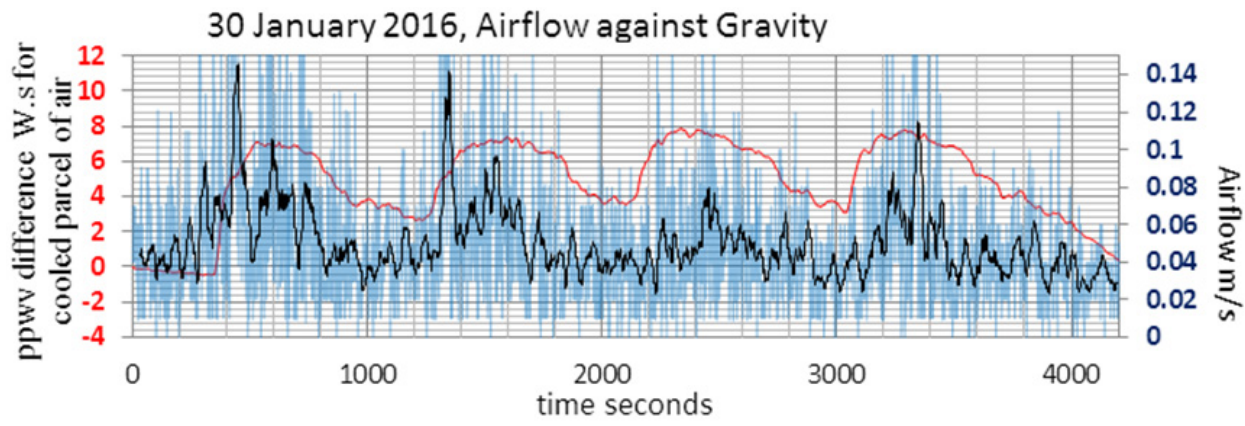

Figure 4 Experiment $30^{\text {th }}$ January, 2016. The left-hand axis shows the partial pressure change as a parcel of air is cooled.The right-hand axis shows the airflow. During the four refrigeration cycles the airflow is directed upwards, against gravity and therefore requires additional work for the air to move.

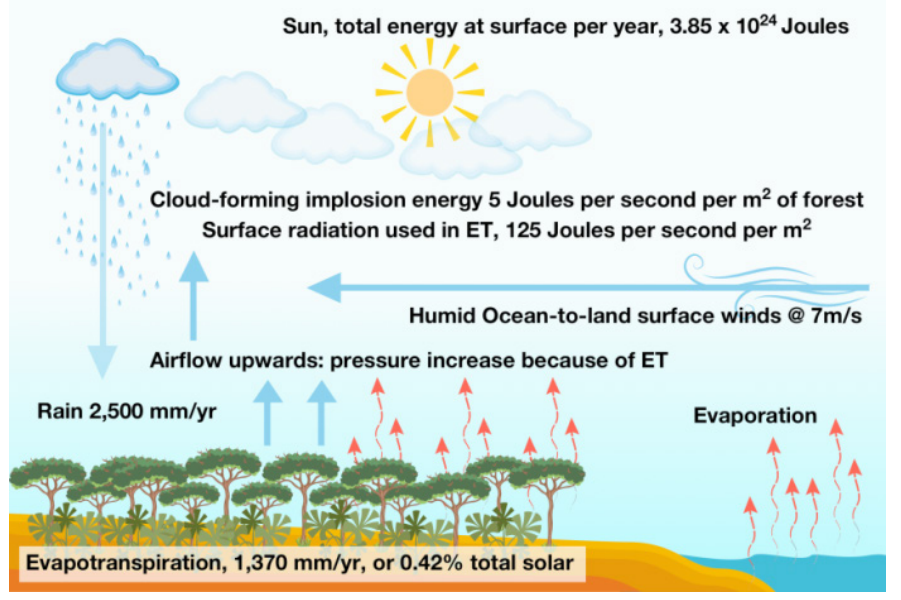

Figure 5 The biotic pump in action.

Source: Peter Bunyard, diagram by Andrew Ayres. 


\section{Experimental evidence of the biotic pump}

To gain further evidence of the association between the condensation of atmospheric water vapour and airflow, Peter Bunyard designed and carried out experiments in a special chamber in which some 20 cubic meters of atmospheric air were enclosed. (Figure 2) Refrigeration, by means of a double layer of cooling coils, resulted in the condensation per second of a few grams of water vapor. A Gill ultrasonic 2D anemometer measured any airflow, including its directionality. By applying ideal gas physics to the air in different parts of the structure so as to measure changes in specific (absolute) humidity, correlations between the rate of condensation and airflow could be determined, ${ }^{2,3}$ and they turned out to be highly significant.

By use of basic physics, ${ }^{2}$ the kinetic energy for the airflow is seen to be derived from the implosion of air surrounding the locus of condensation. That energy is some 1000 times greater than that of air density changes, the latter being insufficient by an order of magnitude to account for the measured airflow.

(The following physical equations account for the energy derived from condensation:

$$
I=\frac{\Delta P a}{\Delta t} m^{3}=1000 \Delta T_{v} \text { and } \Delta T_{v}=0.621 \Delta q T
$$

Where $J$ (joules) is equal to the partial pressure change (Pascal's) over time by volume and $\Delta T_{v}$ is the reduction in temperature by volume as the surrounding air expands into the space vacated by water vapor. The heat capacity of dry air at constant pressure is $1,000 \mathrm{~J} \mathrm{~kg}^{-}$

${ }^{1} \mathrm{~K}^{-1}$. Meanwhile, $\Delta q$ is the absolute humidity change per volume and $T$ is the temperature of the surrounding air (Figure 3 \& Figure 4 ).

The evapotranspiration (ET) over the 5 million square kilometres of the Brazilian Amazon amounts to an average of $1,370 \mathrm{~mm}$ per year. ${ }^{4}$ The kinetic energy associated with the implosion as water vapour from evapotranspiration condenses into clouds translates to some 15 Watt-seconds for every square metre of forested land, during daylight hours. To put that into perspective, I have calculated that the total energies of implosion from water vapour condensation over the entire Brazilian Amazon of 5 million square kilometres amount to the energy equivalent of 327 Hiroshima-size bombs going off every second. In conclusion, the physical evidence suggests that the biotic pump is no longer an abstract theory, but is a principle which needs urgently to be accounted for in those climate models which pertain to rainforest regions such as in the Amazon Basin. Climatologists, by ignoring the BPT, believe widespread deforestation over the Amazon Basin will lead to a transformation from forest to savanna. As seen in Figure 1, the BPT holds that widespread deforestation will lead to desertification in the central and western regions of the Basin. Cities, like Bogotá, in the Eastern Cordillera of the Andes, depend on the airflow from the Amazon Basin to provide essential rains. Were deforestation to continue at its current 2019 pace, the consequences for South America could be devastating.

\section{Acknowledgments}

None.

\section{Conflicts of interest}

The authors declare that there is no conflict of interest.

\section{References}

1. Makarieva AM. Where do winds come from?. A new theory on how water vapor condensation influences atmospheric pressure and dynamics. Atmospheric Chemistry and Physics. 2013;13:1039-1056.

2. Bunyard PP. Condensation and partial pressure change as a major cause of airflow: experimental evidence. DYNA. 2017;84(202):92-101.

3. Bunyard PP. Further experimental evidence that condensation is a major cause of airflow. DYNA. 2019:86(209):56-63.

4. Maeda EE. Evapotranspiration seasonality across the Amazon Basin. Earth Syst Dynam. 2017;8:439-454.

5. Bunyard PP. How the Biotic Pump links the hydrological cycle and the rainforest to climate: Is it for real? How can we prove it? Bogotá, Cundinamarca, Colombia. University of Sergio Arboleda; 2014.

6. Makarieva AA. Biotic pump of atmospheric moisture as driver of the hydrological cycle on land. Hydrology and Earth System Sciences. 2007;11:1013-1033.

7. Marengo JA. On the hydrological cycle of the Amazon Basin: A historical review and current state-of-the-art. Revista Brasileira de Meteorologia. 2006;21(3):1-19.

8. Poveda GA. On the existence of Lloro (the rainiest locality on Earth): Enhanced ocean-land-atmosphere interaction by a low-level jet. Geophysical Research Letters. 2000;27(11):1675-1678.

9. Poveda GL. Seasonal precipitation patterns along pathways of South American low-level jets and aerial rivers. Water Resour Res. 2014:98-118.

10. Salati E. The forest and the hydrological cycle. In R. Dickinson, editor. Geophysiology of Amazonia. New York. Wiley and Sons; 1987:273-296.

11. Spracklen DV. Observations of increased tropical rainfall preceded by air passage over forests. Nature. 2012;489:282-285.

12. Wood RB. Diurnal cycle of liquid water path over the subtropical and tropical oceans. Geophysical Research Letters. 2002;29(23):7-1 -7-4. 